Summer 8-14-2015

\title{
Psychiatric Comorbidities and BMI: An Exploratory Analysis
}

Nicholas Guenzel

University of Nebraska Medical Center

Tell us how you used this information in this short survey.

Follow this and additional works at: https://digitalcommons.unmc.edu/etd

Part of the Psychiatric and Mental Health Nursing Commons

\section{Recommended Citation}

Guenzel, Nicholas, "Psychiatric Comorbidities and BMI: An Exploratory Analysis" (2015). Theses \& Dissertations. 19.

https://digitalcommons.unmc.edu/etd/19

This Dissertation is brought to you for free and open access by the Graduate Studies at DigitalCommons@UNMC. It has been accepted for inclusion in Theses \& Dissertations by an authorized administrator of DigitalCommons@UNMC.For more information, please contact digitalcommons@unmc.edu. 


\title{
Psychiatric Comorbidities and BMI: An Exploratory \\ Analysis
}

\author{
by \\ Nicholas Guenzel \\ A DISSERTATION \\ Presented to the Faculty of \\ the University of Nebraska Graduate College \\ in Partial Fulfillment of the Requirements \\ for the Degree of Doctor of Philosophy
}

Nursing Graduate Program

Under the Supervision of Professor Mary E. Cramer

University of Nebraska Medical Center

Omaha, Nebraska

July, 2015

Supervisory Committee:

Julia F. Houfek, Ph.D. Shinobu Watanabe-Galloway, Ph.D.

Sheila A. Ryan, Ph.D. Daniel J. Schober, Ph.D. 


\title{
PSYCHIATRIC COMORBIDITIES AND BMI: AN EXPLORATORY ANALYSIS
}

\author{
Nicholas Guenzel \\ University of Nebraska, 2015
}

Supervisor: Mary E. Cramer, Ph.D.

Background: Individuals with most forms of mental illness have higher rates of obesity than members of the general public putting them at an increased risk for many physical health problems that reduce both quality of life and life expectancy. The presence of multiple comorbid psychiatric disorders has been associated with poorer clinical outcomes in other mental health measures such as disability and sobriety and is proposed as a risk factor for elevated BMI (body mass index) in this study.

Objective: Determine if multiple psychiatric comorbidities are associated with elevated BMI and, if so, which combinations are linked with the greatest risk.

Design: A secondary analysis of the Collaborative Psychiatric Epidemiology Surveys dataset. The psychiatric disorder group $(\mathrm{N}=7,355)$ included individuals reporting symptoms of one or more mental illnesses. Controls $(\mathrm{N}=12,658)$ included subjects reporting no symptoms suggesting the presence of a psychiatric disorder. BMI was examined using descriptive statistics, t-tests, and Chi-square analyses.

Results: The number of comorbid psychiatric disorders an individual had was associated with BMI. In particular, bipolar disorder, agoraphobia, panic disorder, and attention-deficit hyperactivity (ADHD) disorder had the greatest number of association and the largest effect sizes.

Conclusion: Medical professionals should monitor patients more closely for weight gain when they have multiple psychiatric disorders. Patients with bipolar disorder, agoraphobia, panic disorder, and ADHD should be of particular concern. 
Key Words: comorbidity, psychiatric diagnoses, body mass index 


\section{Table of Contents}

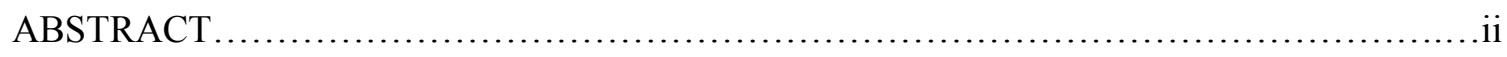

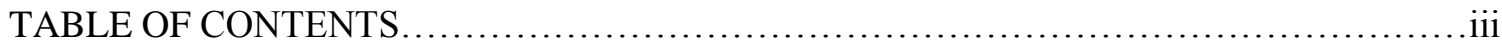

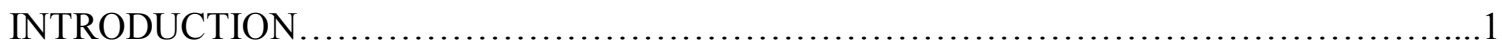

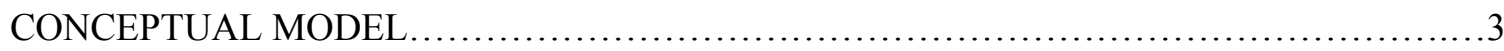

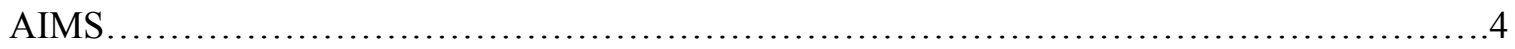

METHODS AND PROCEDURE.........................................................

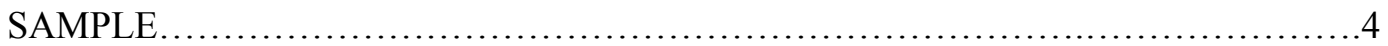

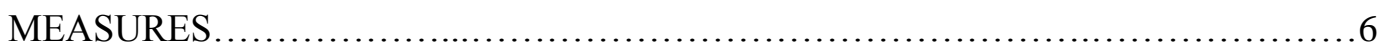

STATISTICAL ANALYSIS...........................................................

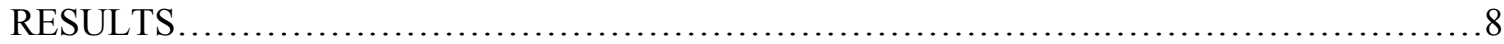

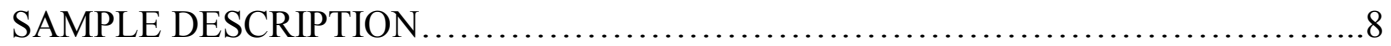

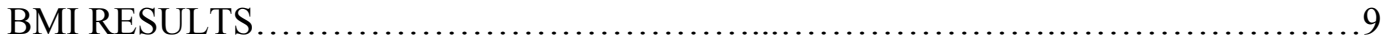

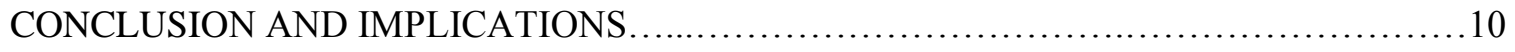

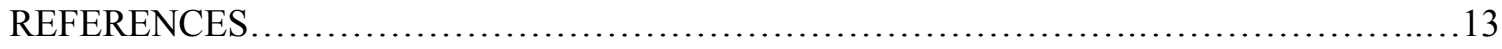

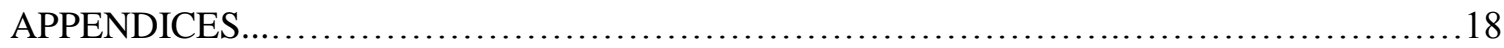


Obesity has been associated with an increased risk for stroke, heart disease, arthritis, diabetes, asthma, chronic back pain, and most forms of cancer (Guh et al., 2009). All of these physical problems reduce quality of life and many of them shorten life expectancy (Kolotkin et al., 2008; Manuel, Schultz, \& Kopec, 2002). Among high-income countries, overweight and obesity has been estimated to account for $7.8 \%$ of deaths and $7.2 \%$ of disability adjusted life years (Lopez \& Mathers, 2006). The direct medical costs of elevated BMI (body mass index) in the United States has been estimated to be almost $\$ 114$ billion, accounting for up to $10 \%$ of healthcare spending (Tsai, Williamson, \& Glick, 2011).

Individuals with a wide variety of psychiatric disorders have been shown to have higher rates of obesity than members of the general public. A meta-analysis found that the presence of depression was associated with a 1.58 times increased risk of developing obesity over individuals without depression (Luppino et al., 2010). A meta-analysis of cross-sectional studies found that individuals with anxiety disorders were at a 1.4 times greater risk for obesity (Gariepy, Nitka, \& Schmitz, 2010). Researchers have found people with schizophrenia and bipolar disorder are at a 3.4 times and 1.7 times higher risk for obesity (Gurpegui et al., 2012; Petry, Barry, Pietrzak, \& Wagner, 2008).

Despite the higher prevalence of obesity among individuals with mental illness, a Cochrane Review of cognitive, behavioral, and pharmacological weight loss programs in this population found that interventions are associated with small effect sizes and a short duration of impact (Faulkner, Cohn, \& Remington, 2009). As a result, the prevention of obesity among individuals with psychiatric problems may hold greater promise than weight loss programs. However, the widespread use of preventative interventions can be costly and may expose individuals at low risk for gaining weight to potential adverse effects. For example, the use of medication to help with appetite control may expose some individuals to side effects or allergic 
reactions. As a result, it is essential to explore early risk factors for the development of obesity in order to identify individuals who require the most intensive interventions.

A variety of explanations have been proposed for the increased rates of obesity seen among individuals with mental illness. It is likely that some secondary factors associated with mental illness, such as socioeconomic status, play a role in this phenomenon (Guenzel, 2015). However, it is also logical to deduce that some symptoms of the psychiatric disorders themselves are at fault such as alterations in neurological reward pathways and increased appetite (Grimm, Vollstädt-Klein, Krebs, Zink, \& Smolka, 2012). Little research has been conducted to examine these relationships, but a number of mechanisms have been proposed. For example, among individuals with attention-deficit hyperactivity disorder (ADHD), it has been hypothesized that binge eating behaviors and food as a form of self-medication contribute to weight gain (Davis, 2010).

Research has examined some effects of comorbid psychiatric disorders. Specifically, one systematic review found that anxiety comorbid with schizophrenia was associated with increased symptoms and poorer outcomes (Braga, Reynolds, \& Siris, 2013). Another study found that individuals who had anxiety or depression in addition to an alcohol use disorder were more disabled and drank more after treatment than those without anxiety or depression (Burns, Teesson, \& O'Neill, 2005).

The researchers hypothesize that the presence of multiple psychiatric disorders may be associated with higher rates of obesity. Based on previous research regarding associations between the symptoms of various forms of mental illness and obesity, there is reason to infer that the effects of multiple comorbid psychiatric disorders may compound to result in an even greater risk for elevated BMI. For example, if an individual has the altered reward pathways associated with schizophrenia in addition to the binge eating behaviors sometimes seen with ADHD we can see how his or her risk of weight gain may be higher than if he or she had either disorder alone. 
Once specific combinations of disorders that lead to the greatest risk of obesity are identified, practitioners can use this information in screening and offering more intensive weight management interventions. The purpose of this article is determine if the presence of multiple psychiatric comorbidities is associated with elevated BMI.

\section{Conceptual Model}

The conceptual model developed for this article is based on the hypothesis that the presence of multiple comorbid psychiatric disorders increases the risk for obesity (see Appendix A). This model proposes that multiple psychiatric disorders are associated with an elevated symptom burden. No consensus exists regarding the definition of symptom burden in mental health, but for the purposes of this model, symptom burden has been defined as an increased number, intensity, frequency and/or duration of psychiatric symptoms. It is inferred that an elevated symptom burden often leads to increased numbers and doses of medications, lower socioeconomic status, more numerous and severe health problems, physical inactivity, and poorer dietary habits. These factors then increase an individual's risk for developing obesity.

A number of interrelationships are possible within this model. Specifically, obesity can lead to reduced SES, health problems, physical inactivity, and a poor diet (Baum \& Ford, 2004; Guh et al., 2009; Tucker, Tucker, LeCheminant, \& Bailey, 2013). Higher levels of many psychiatric medications can lead to health problems and poor dietary patterns (Cuerda, Velasco, Merchán-Naranjo, García-Peris, \& Arango, 2014; Limosin, Gasquet, Leguay, Azorin, \& Rouillon, 2008; McIntyre, 2009). Low SES is often associated with health problems, physical inactivity, and poor dietary patterns (Gordon-Larsen, Nelson, Page, \& Popkin, 2006; Kanjilal et al., 2006; Wang \& Chen, 2011). Health problems can lead to physical inactivity and vice-versa (Lee et al., 2012; Sokka et al., 2008). It has also been well documented that poor dietary habits can lead to a wide variety of health problems (Jakobsen et al., 2009; Malik et al., 2010). Lastly, 
low SES, health problems, physical inactivity, and poor diet can all lead to elevated symptom burden (Jacka et al., 2010; Luppino et al., 2010; Ströhle, 2009).

\begin{abstract}
Aims
The model is designed to test the three specific aims of this study:

1. Determine if more than one psychiatric comorbidities is associated with elevated BMI.

It is hypothesized that subjects with multiple mental health conditions will have a higher BMI than those without any psychiatric disorders.
\end{abstract}

2. Identify which comorbid mental health conditions are most strongly associated with an increased risk for elevated BMI.

It is hypothesized that some psychiatric disorders will be associated with a greater risk of elevated BMI than others.

3. Determine if the number of psychiatric disorders is associated with elevated BMI.

It is hypothesized that as the number of psychiatric disorders increases BMI will increase also.

\title{
Methods and Procedure
}

This study was conducted as a secondary analysis of the Collaborative Psychiatric Epidemiology Surveys (CPES) dataset using a descriptive case-control design.

\section{Sample}

The CPES dataset contains information on 20,013 community-dwelling individuals over the age of 18. Participants were selected with the use of multi-stage randomized sampling in 252 geographic areas across the United States (Alegria, Jackson, Kessler, \& Takeuchi, 2009). The weighted randomization procedure produced a sample which likely represents communitydwelling adults in the United States who would report having symptoms of the various disorders in a clinical interview (Heeringa et al., 2004). 
The CPES dataset was comprised of three survey interviews conducted between 2001 and 2003 (Alegria, Jackson, Kessler, \& Takeuchi, 2009). Interviews were conducted in participants' homes by lay personnel using a computer program. The data was collected based on self-report and then combined into a single dataset. Personal identifying information was removed for the publically-available dataset and this version was sufficient for the current study.

The CPES was based on the Composite International Diagnostic Interview (CIDI). The CIDI was developed for the World Mental Health Survey Initiative and has been used since the 1990s (Wittchen, 1994). The structured interview was intended for use in the field by lay individuals to produce diagnoses based on the World Health Organization's International Classification of Disease Criteria and the American Psychiatric Association's Diagnostic and Statistical Manual (Alegria, Jackson, Kessler, \& Takeuchi, 2009). Studies examining the CIDI have found that its use by lay individuals produces diagnoses similar to those identified by clinicians using semi-structured interviews. In addition, researchers have shown the CIDI to have a concordance rate of 0.76 with the Structured Clinical Interview for the DSM-IV (Haro et al., 2006).

Furthermore, studies have shown that the CIDI has higher test-retest reliability than semistructured interviews conducted by clinicians (Kendler, Gallagher, Abelson, \& Kessler, 1996).The CIDI asks respondents a large number of questions about symptoms of all the major forms of mental illness. Based on the responses, the CIDI produces probable diagnoses. The disorders identified by the CIDI include major depression, bipolar disorder, alcohol use disorders (alcohol abuse or alcohol dependence), drug use disorders (drug abuse or drug dependence), conduct disorder, intermittent explosive disorder, oppositional defiant disorder, attention deficit hyperactivity disorder, generalized anxiety disorder, panic disorder, separation anxiety, social phobia, agoraphobia, specific phobia, and post-traumatic stress disorder. 
The CIDI does not identify participants who likely have schizophrenia. The survey did, however, elicit information on specific positive and negative symptoms in addition to psychiatric history. For this study, individuals who reported positive and negative symptoms consistent with a diagnosis of schizophrenia were included as having this disorder. In addition, participants who reported ever having been diagnosed with or disabled by schizophrenia were regarded as having the condition.

\section{Measures}

The current study included all participants who reported symptoms consistent with a diagnosis of schizophrenia, major depressive disorder, bipolar disorder, alcohol use disorders, drug use disorders, conduct disorder, intermittent explosive disorder, oppositional defiant disorder, attention deficit hyperactivity disorder, generalized anxiety disorder, panic disorder, separation anxiety, social phobia, agoraphobia, specific phobia, and post-traumatic stress disorder. Participants who reported symptoms consistent with DSM-IV criteria for the disorders listed previously were included in the respective mental illness groups. Participants who reported having symptoms consistent with any of the disorders listed above were included in the control group.

Subject-reported height and weight were used to calculate body mass index (BMI) according to the following formula: weight in kilograms / (height in meters) ${ }^{2}$ (Alegria et al., 2009). Research has found that men tend to overestimate their height and weight whereas women overestimate their height and underestimate their weight (Merrill \& Richardson, 2009). However, the same study found that men underestimated their BMI by only 0.34 units while women overestimated their BMI by 0.82 units. Errors of this size are not likely to skew the overall patterns of results within this study. Furthermore, we have no reason to believe that the accuracy of self-reported height and weight varies between individuals with mental illness and those without mental illness. 


\section{Statistical Analysis}

The statistical analyses were performed using SPSS 23 (IBM Corp., 2015). The effect size of each t-test was calculated using the mean and standard deviation in a frequently used online tool (Becker, 1999). In addition, the power of most analyses was calculated using G-Power 3.0.10 (Faul, Erdfelder, Lang, \& Buchner, 2007). Results were considered significant at a p-value of less than 0.05 .

The frequency of each psychiatric disorder was calculated. Next, the mean and frequency calculations were completed for the demographic variables of participants within the psychiatric group and the control group including ages, sex, proportion of minorities, marital status, and education.

\section{Aim 1. Determine if more than one psychiatric comorbidity is associated with elevated BMI.}

Independent samples t-tests were used to compare the BMI of participants within the control group to participants with each psychiatric disorder. The same process was used to compare the BMI of participants in the control group to the BMI of participants with each combination of disorders. For example, the BMI of individuals with schizophrenia and social phobia was compared to the BMI of the control participants.

\section{Aim 2. Identify which comorbid mental health conditions are most strongly associated with an increased risk for elevated BMI.}

The number of significant associations among the various psychiatric disorders was assessed (see Appendix D). For example, the number of comorbid disorders in addition to bipolar disorder was compared to the number of comorbid disorders with generalized anxiety disorder. Second, the effect size of these relationships were compared. 


\section{Aim 3. Determine if the number of psychiatric disorders is associated with elevated BMI.}

A Spearman's Rho correlation was run to examine the relationship between number of psychiatric disorders and BMI. Independent samples t-tests were then run comparing the BMI of participants with two or more disorders to participants with one disorder. The same process was repeated, comparing participants with three or more disorders to participants with participants reporting two or fewer disorders and four or more disorders with participants with three or fewer disorders.

\section{Results}

\section{Sample Description}

The potential sample included a total of 20,013 participants. Analyses found 7,355 individuals with one or more mental illnesses and 12,658 participants with no mental illnesses.

The sample size and prevalence data for the various disorders is listed in Appendix B. The prevalence rates were fairly similar to what has been found in the general US population (Reeves et al., 2011).

Demographic calculations revealed that individuals in the psychiatric disorders group were younger (40.0 years v. 45.3 years, $t(23)=22.94, p<0.001)$ and less likely to married $\left(49.6 \%\right.$ v. $\left.56 \%, \chi^{2}(1, \mathrm{~N}=20,003)=78.45, p<0.001\right)$. Relative to the control group, the psychiatric disorders group had fewer minorities $\left(53.3 \%\right.$ v. $60.4 \%, \chi^{2}(1, \mathrm{~N}=17,910)=87.87, p<$ $0.001)$, a similar proportion of females $\left(58.1 \%\right.$ v. $\left.56.8 \%, \chi^{2}(1, \mathrm{~N}=20,003)=2.98, p=0.084\right)$, and a similar proportion had studied beyond high school $\left(50.1 \%\right.$ v. $50.1 \%, \chi^{2}(1, \mathrm{~N}=20,013)=0$, $p=0.987)$.

Appendix $\mathrm{C}$ displays the frequency of the number of disorders among the psychiatric disorders group. For example, 3,194 (43.4\%) had one disorder, 1,602 (21.8\%) had two disorders. 


\section{BMI Results}

Of the 15 disorders examined in this study, six of the disorders, separately, were found to be significantly associated with elevated BMI when compared with individuals with no psychiatric disorders. These conditions included bipolar disorder, ADHD, post-traumatic stress disorder (PTSD), panic disorder, agoraphobia, and separation anxiety disorder. The effect sizes of these relationships were relatively small, ranging from 0.20 to 0.26 .

\section{Aim 1. Determine if more than one psychiatric comorbidities is associated with elevated BMI.}

The BMI of participants with each combination of two disorders was compared with individuals with no psychiatric disorders, resulting in 132 combinations. Of these, 34 were statistically significant with an effect size of $d=0.3$ or greater. These results were grouped by the number of cormorbidities and the effect size associated with these relationships (see Appendices 3 and 4).

\section{Aim 2. Identify which comorbid mental health conditions are most strongly associated with an increased risk for elevated BMI.}

The four disorders with the most numerous significant comorbidities associated with BMI were bipolar disorder, agoraphobia, attention-deficit hyperactivity disorder, and panic disorder (see Appendix E). Bipolar disorder in the presence of eleven other disorders was significantly associated with elevated BMI. The mean effect size of these eleven relationships was 0.42. Agoraphobia with nine other disorders was associated with BMI with an average effect size of 0.44. ADHD comorbid with eight other disorders was linked with higher BMI and an average effect size of 0.42 . Lastly, panic disorder in the presence of seven other disorders was associated with elevated BMI and an average effect size of 0.38 . 


\section{Aim 3. Determine if the number of psychiatric disorders is associated with elevated BMI.}

A Spearman's Rho correlation showed that the number of psychiatric disorders was not associated with BMI $\left(\mathrm{r}_{\mathrm{s}}=0.035, p<0.001\right)$. As a result, it appears that individuals with a higher number of psychiatric disorders are not necessarily at greater risk for having an elevated BMI. Ttests revealed that participants with two or more disorders had a BMI that was statistically greater than participants with one disorder, but the effect size was negligible $(27.8$ v. $27.2, t(6,607)=$ $3.637, p<0.001, \mathrm{~d}=0.09)$. The same was found regarding participants with three or more disorders compared to participants with two or fewer disorders $(27.8$ v. $27.4, t(4,572)=2.493, p$ $=0.013, \mathrm{~d}=0.06)$. The mean BMI did not differ statistically between participants with four or more disorders and participants with three or fewer disorders $(27.9$ v. $27.7, t(3,852)=0.986, p$ $=0.342, \mathrm{~d}=0.03)$.

\section{Conclusions and Implications}

This study adds to the understanding of some of the complex relationships that exist between mental illness and BMI. Previous studies have established that individuals with a wide variety of mental health conditions are at an increased risk for elevated BMI. However, little research has examined associations with multiple comorbid psychiatric disorders.

Perhaps the most important result uncovered by this research is that no evidence was found that most comorbid psychiatric disorders are associated with an increased risk for elevated BMI. Rather, a relatively small number of cormorbidities were associated with BMI. The effect sizes of the significant associations ranged from $\mathrm{d}=0.3$ to $\mathrm{d}=0.7$.

Four disorders were found to have the largest number of comorbid psychiatric disorders associated with elevated BMI. Specifically, providers could easily incorporate most of the findings by simply remembering that bipolar disorder, agoraphobia, attention-deficit hyperactivity disorder, and panic disorder in the presence of most other disorders may put 
patients at an increased risk for developing obesity. As a result, when such patients are seen, height, weight, and BMI should be tracked more closely. In addition, weight management interventions such as dietary education and exercise should be focused most intensively on patients at the highest risk for obesity. All of the information needed to implement the current findings should be produced either through a standard diagnostic interview or a review of the existing chart. In most cases, no additional information needs to be obtained from patients.

The current study found that only six of the sixteen disorders examined were associated with elevated BMI by themselves. Furthermore, the effect sizes of these associations were relatively small (d=0.2-0.26). By contrast, 34 combinations of disorders were associated with a significant risk for elevated BMI with an effect size of at least 0.3 .

There were a number of limitations in this study. Some of the limitations originated from the fact that the participants did not fit within mutually exclusive groups. For example, an individual could have bipolar disorder, generalized anxiety disorder, and an alcohol use disorder. As a result, statistical methods such as ANOVAs could not be used to compare BMIs between individuals with various psychiatric diagnoses. Establishing mutually exclusive groups that include specific disorders while excluding others may be a viable approach for future research, but would not have been feasible for the current study as it would require hundreds of calculations.

It is acknowledged that t-tests and Spearman correlations are rather basic statistical tools. However, two factors prevented the use of more sophisticated techniques such as regression models capable of factoring in the impact of variables such as sex, age, and others. First, the data set itself has a significant number of gaps in which certain participants were asked some groups of questions whereas others were not. Second, the large number of groups established in this research would require the development of hundreds of regression models. Even limiting the models to the 34 relationships found to be significant would be cumbersome and limited due to 
gaps in the data set. Unfortunately, the current results cannot be compared with previous research as this is the first analysis of comorbid psychiatric disorders and BMI.

The current research did have a number of strengths. First, the extensive randomization in the selection of subjects produced a sample which is likely representative of members of the general public. Because controls were selected from the same population using the same methods as participants in the psychiatric disorders group, we can have a high degree of confidence in their comparisons. Second, due to the comprehensive nature of the surveys, we were able to examine the combinations of most psychiatric disorders. Third, the overall survey included a very large number of questions so it is very unlikely that the participants systematically altered their responses based on perceived researcher expectations.

Future research could focus more on the disorders that were found to be associated with an elevated BMI in this study. An examination fewer groups would allow for a more detailed examination of a larger number of variables. Specifically, sex, age, dietary factors, and exercise habits could be analyzed in this population.

The current study provides some guidance to medical professionals in helping their patients to maintain a healthy weight. Patients with multiple comorbid psychiatric disorders should be monitored more closely and considered for more intensive weight management interventions. In particular, patients who have agoraphobia, bipolar disorder, panic disorder, or ADHD in addition to at least one other disorder should be receive special attention in this area. This is not to say that the current study provides evidence to support the relaxed monitoring of patients with other disorders as the sample sizes were often too small to determine if a significant relationship exists. Obesity remains a significant challenge for psychiatric patients and their providers. We can start to control this epidemic by identifying people at greatest risk, offering weight management interventions, and by remaining vigilant in monitoring for weight gain. 


\section{References}

Alegria, M., Jackson, J., Kessler, R., \& Takeuchi, D. (2009). Collaborative psychiatric epidemiology surveys (CPES), 2001-2003. Institute for Social Research, Survey Research Center and Inter-University Consortium for Political and Social Research, Ann Arbor, MI.Http://Www.Icpsr.Umich.Edu/CPES/

Baum, C. L., \& Ford, W. F. (2004). The wage effects of obesity: A longitudinal study. Health Economics, 13(9), 885-899.

Cuerda, C., Velasco, C., Merchán-Naranjo, J., García-Peris, P., \& Arango, C. (2014). The effects of second-generation antipsychotics on food intake, resting energy expenditure and physical activity. European Journal of Clinical Nutrition, 68(2), 146-152.

Faul, F., Erdfelder, E., Lang, A., \& Buchner, A. (2007). G* power 3: A flexible statistical power analysis program for the social, behavioral, and biomedical sciences. Behavior Research Methods, 39(2), 175-191.

Faulkner, G., Cohn, T., \& Remington, G. (2009). Interventions to reduce weight gain in schizophrenia. The Cochrane Library.

Gordon-Larsen, P., Nelson, M. C., Page, P., \& Popkin, B. M. (2006). Inequality in the built environment underlies key health disparities in physical activity and obesity. Pediatrics, $117(2), 417-424$.

Grimm, O., Vollstädt-Klein, S., Krebs, L., Zink, M., \& Smolka, M. (2012). Reduced striatal activation during reward anticipation due to appetite-provoking cues in chronic schizophrenia: A fMRI study. Schizophrenia Research, 134(2), 151-157.

Guenzel, N (2015). Association between socioeconomic status and obesity among people with 
schizophrenia and bipolar disorder. University of Nebraska Medical Center, Omaha, Nebraska.

Guh, D. P., Zhang, W., Bansback, N., Amarsi, Z., Birmingham, C. L., \& Anis, A. H. (2009). The incidence of co-morbidities related to obesity and overweight: A systematic review and metaanalysis. BMC Public Health, 9, 88-88.

Gurpegui, M., Martínez-Ortega, J. M., Gutiérrez-Rojas, L., Rivero, J., Rojas, C., \& Jurado, D. (2012). Overweight and obesity in patients with bipolar disorder or schizophrenia compared with a non-psychiatric sample. Progress in Neuro-Psychopharmacology \& Biological Psychiatry, 37(1), 169-175.

Haro, J. M., Arbabzadeh-Bouchez, S., Brugha, T. S., De Girolamo, G., Guyer, M. E., Jin, R., ... \& Kessler, R. C. (2006). Concordance of the Composite International Diagnostic Interview Version 3.0 (CIDI 3.0) with standardized clinical assessments in the WHO World Mental Health surveys. International Journal of Methods in Psychiatric Research, 15(4), 167-180.

Heeringa, S. G., Wagner, J., Torres, M., Duan, N., Adams, T., \& Berglund, P. (2004). Sample designs and sampling methods for the collaborative psychiatric epidemiology studies (CPES). International Journal of Methods in Psychiatric Research, 13(4), 221-240.

Jacka, F. N., Pasco, J. A., Mykletun, A., Williams, L. J., Hodge, A. M., O'Reilly, S. L., . . Berk, M. (2010). Association of western and traditional diets with depression and anxiety in women. The American Journal of Psychiatry, 167(3), 305-311.

IBM Corp. Released 2015. IBM SPSS Statistics for Windows, Version 23.0. Armonk, NY: IBM Corp. 
Jakobsen, M. U., O'Reilly, E. J., Heitmann, B. L., Pereira, M. A., Balter, K., Fraser, G. E., . . . Ascherio, A. (2009). Major types of dietary fat and risk of coronary heart disease: A pooled analysis of 11 cohort studies. The American Journal of Clinical Nutrition, 89(5), 1425-1432.

Kanjilal, S., Gregg, E. W., Cheng, Y. J., Zhang, P., Nelson, D. E., Mensah, G., \& Beckles, G. L. (2006). Socioeconomic status and trends in disparities in 4 major risk factors for cardiovascular disease among US adults, 1971-2002. Archives of Internal Medicine, 166(21), $2348-2355$.

Kolotkin, R. L., Corey-Lisle, P., Crosby, R. D., Swanson, J. M., Tuomari, A. V., L'italien, G.,J., \& Mitchell, J. E. (2008). Impact of obesity on health-related quality of life in schizophrenia and bipolar disorder. Obesity (Silver Spring, Md.), 16(4), 749-754.

Lee, I., Shiroma, E. J., Lobelo, F., Puska, P., Blair, S. N., Katzmarzyk, P. T., \& Lancet Physical Activity Series Working Group. (2012). Effect of physical inactivity on major noncommunicable diseases worldwide: An analysis of burden of disease and life expectancy. The Lancet, 380(9838), 219-229.

Limosin, F., Gasquet, I., Leguay, D., Azorin, J., \& Rouillon, F. (2008). Body mass index and prevalence of obesity in a french cohort of patients with schizophrenia. Acta Psychiatrica Scandinavica, 118(1), 19-25.

Lopez, A. D., \& Mathers, C. D. (2006). Measuring the global burden of disease and epidemiological transitions: 2002-2030. Annals of Tropical Medicine and Parasitology, 100(5-6), 481-499. 
Luppino, F. S., de Wit, L. M., Bouvy, P. F., Stijnen, T., Cuijpers, P., Penninx, B. W., \& Zitman, F. G. (2010). Overweight, obesity, and depression: A systematic review and meta-analysis of longitudinal studies. Archives of General Psychiatry, 67(3), 220.

Malik, V. S., Popkin, B. M., Bray, G. A., Despres, J. P., Willett, W. C., \& Hu, F. B. (2010). Sugar-sweetened beverages and risk of metabolic syndrome and type 2 diabetes: A metaanalysis. Diabetes Care, 33(11), 2477-2483.

Manuel, D., Schultz, S., \& Kopec, J. (2002). Measuring the health burden of chronic disease and injury using health adjusted life expectancy and the health utilities index. Journal of Epidemiology and Community Health, 56(11), 843-850.

McIntyre, R. S. (2009). Managing weight gain in patients with severe mental illness. The Journal of Clinical Psychiatry, 70(7), e23-e23.

Merrill, R. M., \& Richardson, J. S. (2009). Validity of self-reported height, weight, and body mass index: Findings from the national health and nutrition examination survey, 2001-2006. Prev Chronic Dis, 6(4), A121.

Petry, N. M., Barry, D., Pietrzak, R. H., \& Wagner, J. A. (2008). Overweight and obesity are associated with psychiatric disorders: Results from the national epidemiologic survey on alcohol and related conditions. Psychosomatic Medicine, 70(3), 288-297.

Reeves, W. C., Strine, T. W., Pratt, L. A., Thompson, W., Ahluwalia, I., Dhingra, S. S., . . Williams, L. (2011). Mental illness surveillance among adults in the united states. Morbidity and Mortality Weekly Report: Surveillance Summary, 60(Suppl 3), 1-29. 
Sokka, T., Häkkinen, A., Kautiainen, H., Maillefert, J. F., Toloza, S., Calvo-Alen, J., . . Alten, R. (2008). Physical inactivity in patients with rheumatoid arthritis: Data from twenty-one countries in a cross-sectional, international study. Arthritis Care \& Research, 59(1), 42-50.

Ströhle, A. (2009). Physical activity, exercise, depression and anxiety disorders. Journal of Neural Transmission, 116(6), 777-784.

Tsai, A. G., Williamson, D. F., \& Glick, H. A. (2011). Direct medical cost of overweight and obesity in the USA: A quantitative systematic review. Obesity Reviews, 12(1), 50-61.

Tucker, J. M., Tucker, L. A., LeCheminant, J., \& Bailey, B. (2013). Obesity increases risk of declining physical activity over time in women: A prospective cohort study. Obesity, 21(12), E715-E720.

Wang, Y., \& Chen, X. (2011). How much of racial/ethnic disparities in dietary intakes, exercise, and weight status can be explained by nutrition-and health-related psychosocial factors and socioeconomic status among US adults? Journal of the American Dietetic Association, 111(12), 1904-1911. 


\section{Appendix A}

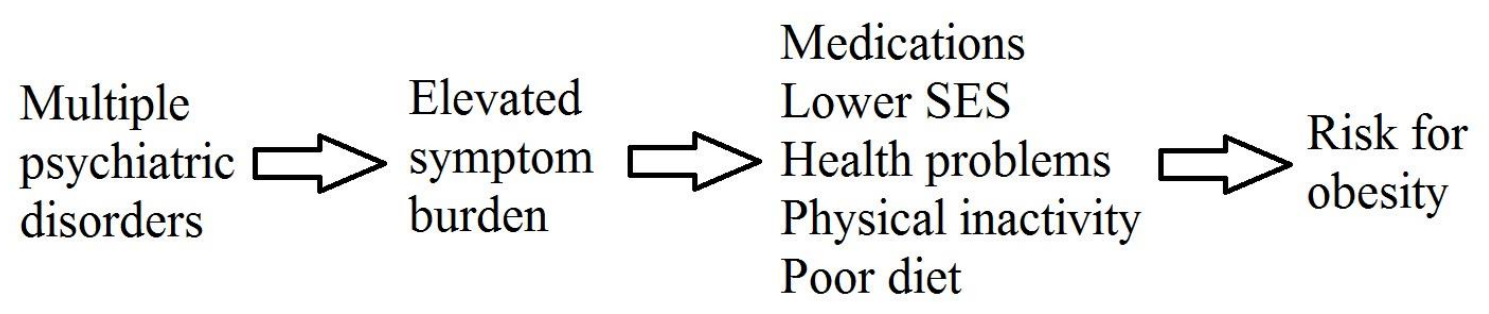

Proposed Conceptual Model 


\section{Appendix B}

\begin{tabular}{|l|l|l|}
\hline Diagnosis & $\mathrm{n}$ & prevalence \\
\hline Schizophrenia & 181 & 0.9 \\
\hline Major depressive disorder & 3,241 & 13.1 \\
\hline Bipolar disorder & 299 & 1.5 \\
\hline Alcohol use disorders & 1,725 & 8.6 \\
\hline Drug use disorders & 1,087 & 5.4 \\
\hline Conduct disorder & 2,491 & 10.6 \\
\hline Intermittent explosive disorder & 975 & 4.9 \\
\hline Oppositional defiant disorder & 689 & 3.4 \\
\hline Attention deficit hyperactivity disorder & 518 & 5 \\
\hline Generalized anxiety disorder & 1,220 & 6.1 \\
\hline Panic disorder & 4,635 & 4.1 \\
\hline Separation anxiety & 552 & 2.8 \\
\hline Social phobia & 1,909 & 8 \\
\hline Agoraphobia & 495 & 2.5 \\
\hline Specific phobia & 1,198 & 6 \\
\hline Post-traumatic stress disorder & 1,194 & 6 \\
\hline
\end{tabular}

Prevalence of Psychiatric Disorders in Sample 


\section{Appendix C}

\begin{tabular}{|l|l|l|}
\hline $\begin{array}{l}\text { Number of } \\
\text { disorders }\end{array}$ & $\mathrm{n}$ & Percentage \\
\hline 1 & 3,194 & 43.4 \\
\hline 2 & 1,602 & 21.8 \\
\hline 3 & 1,005 & 13.7 \\
\hline 4 & 604 & 8.2 \\
\hline 5 & 395 & 5.4 \\
\hline 6 & 237 & 3.2 \\
\hline 7 & 149 & 2 \\
\hline
\end{tabular}

Prevalence of the Number of Comorbid Disorders in the Psychiatric Disorders Group 


\section{Appendix D}

\begin{tabular}{|l|l|l|}
\hline Disorder & $\begin{array}{l}\text { Number of significant } \\
\text { comorbidities }\end{array}$ & Average effect size \\
\hline Bipolar disorder & 11 & 0.424 \\
\hline Agoraphobia & 9 & 0.444 \\
\hline ADHD & 8 & 0.424 \\
\hline Panic disorder & 7 & 0.383 \\
\hline PTSD & 5 & 0.388 \\
\hline Separation anxiety & 5 & 0.418 \\
\hline Social phobia & 4 & 0.358 \\
\hline GAD & 4 & 0.345 \\
\hline Specific phobia & 4 & 0.338 \\
\hline MDD & 3 & 0.323 \\
\hline Drug use disorder & 3 & 0.31 \\
\hline IED & 2 & 0.35 \\
\hline ODD & 1 & 0.5 \\
\hline Conduct disorder & 1 & 0.32 \\
\hline
\end{tabular}

Number of Comorbidities and Average Effect Size 


\section{Appendix E}

\begin{tabular}{|c|c|c|c|c|c|}
\hline Agoraphobia & Bipolar disorder & 0.72 & $\begin{array}{l}\text { Bipolar } \\
\text { disorder }\end{array}$ & Agoraphobia & 0.72 \\
\hline & ADHD & 0.60 & & ADHD & 0.55 \\
\hline & ODD & 0.50 & & PTSD & 0.46 \\
\hline & Separation anxiety & 0.48 & & $\begin{array}{l}\text { Separation } \\
\text { anxiety }\end{array}$ & 0.42 \\
\hline & Panic disorder & 0.37 & & Social phobia & 0.39 \\
\hline & $\begin{array}{l}\text { Major depressive } \\
\text { disorder }\end{array}$ & 0.35 & & IED & 0.38 \\
\hline & GAD & 0.35 & & Panic disorder & 0.38 \\
\hline & IED & 0.32 & & GAD & 0.36 \\
\hline & Drug & 0.31 & & $\begin{array}{l}\text { Drug use } \\
\text { disorder }\end{array}$ & 0.36 \\
\hline & & & & $\begin{array}{l}\text { Conduct } \\
\text { disorder }\end{array}$ & 0.32 \\
\hline $\begin{array}{l}\text { Panic } \\
\text { disorder }\end{array}$ & ADHD & 0.52 & ADHD & Agoraphobia & 0.6 \\
\hline & Separation anxiety & 0.43 & & Bipolar disorder & 0.55 \\
\hline & Bipolar disorder & 0.38 & & Panic disorder & 0.52 \\
\hline & Social phobia & 0.37 & & PTSD & 0.46 \\
\hline & Agoraphobia & 0.37 & & Specific Phobia & 0.38 \\
\hline & Specific phobia & 0.31 & & $\begin{array}{l}\text { Separation } \\
\text { anxiety }\end{array}$ & 0.37 \\
\hline & $\begin{array}{l}\text { Major depressive } \\
\text { disorder }\end{array}$ & 0.3 & & GAD & 0.36 \\
\hline & & & & Social phobia & 0.35 \\
\hline & & & & $\begin{array}{l}\text { Major } \\
\text { depressive } \\
\text { disorder }\end{array}$ & 0.32 \\
\hline
\end{tabular}

Disorders with the Greatest Number of Significant Comorbid Disorders and their Effect Sizes 